Revista de Estudios Histórico-Jurídicos

[Sección Historia del Derecho Chileno]

XXXV (Valparaíso, Chile, 2013)

[pp. $547-566$ ]

\title{
MERCANTILISMO, PROTECCIONISMO Y ORDEN PÚBLICO ECONÓMICO EN EL PENSAMIENTO CONSTITUCIONAL DE JUAN EGAÑA
}

[Mercantilism, Protectionism and Public Economic Order in the Constitutional Thought of Juan Egaña]

\author{
JaVier Francisco Infante Martin* \\ Sociedad Chilena de Historia y Geografía \\ Pontificia Universidad Católica de Chile
}

\section{RESUMEN}

Los principios liberales a los cuales adhería Juan Egaña, tales como libertad económica, propiedad privada y rol subsidiario del Estado, quedan de manifiesto a lo largo de su obra. El trabajo estudia tales conceptos para dejar en evidencia el pensamiento económico del autor, que prácticamente no ha sido objeto de examern.

\section{Palabras Clave}

Juan Egaña - Libertad individual Propiedad privada, - Libertad de comercio - Estado subsidiario.

\section{AbSTRACT}

The liberal principles Juan Egaña embraced, such as economic freedom, private property and the subsidiary role of the State, can be clearly seen throughout his work. This article studies said concepts to evidence the hardly studied, economical thought of the author.

\section{KeYwords}

Juan Egaña - Individual freedom Private property - Free trade - Subsidiary State.

ReCibIDO el 21 de marzo ACEPTADO el 10 de mayo de 2013

* Doctor en Derecho por la Universidad de Navarra, España. Profesor de Historia del Derecho en la Pontificia Universidad Católica de Valparaíso. Dirección postal: Facultad de Derecho, Pontificia Universidad Católica de Valparaíso, Avda. Brasil 2950, Valparaíso, Chile. Correo electrónico: jinfante@alumni.unav.es 


\section{INTRODUCCIÓN}

La obra de Egaña merece ser revisada por varios motivos. En primer lugar, fue quizá el pensador republicano más prolífero en los inicios de nuestra vida independiente. La vastedad de su obra conlleva per se un difícil trabajo para el historiador, el cual debe recurrir a una multitud de trabajos monográficos, publicaciones periódicas, su amplio repertorio epistolar y su trabajo como legislador. Un segundo motivo, y consecuencia del anterior, es la profundidad filosófica, política y jurídica de su obra. Si bien no son características que vayan necesariamente de la mano, lo cierto es que la obra de Egaña no sólo es vasta, sino que de un gran contenido, que abarca los grandes temas de la política: la moral, la economía, la propiedad, los derechos individuales y la forma de gobierno. Un tercer motivo se debe a la "mala prensa" que el autor ha recibido a lo largo de nuestra breve historia. Esta errada lectura que se ha hecho -salvo contados casos- sobre la obra de Juan Egaña amerita el reivindicar su persona al sitial que en nuestro juicio le corresponde: el de uno de los padres fundadores de la República.

Nuestra historiografía ha encontrado a nuestros próceres en figuras de gran mérito, pero cuya obra se agota en determinados campos: Carrera y $\mathrm{O}^{\prime} \mathrm{Higgins}$ en nuestra historia militar, Diego Portales en la fundación del régimen del orden, o Ramón Freire en el paso del protectorado de la Patria Vieja a la instauración de la República. Sin embargo, autores como Henríquez, Salas, Infante, Rodríguez Aldea o Juan Egaña, han sido relegados a un segundo plano. Quizá el afán militarista en la búsqueda de héroes de espada nos ha impulsado en este sentido.

Nuestro trabajo pretende comenzar la restauración de la figura de nuestros próceres de pluma. Si bien algunos de ellos ciñeron la espada en alguna ocasión, los cierto es que la mayoría de su labor fue dedicada a la construcción de nuestra nación, de nuestra identidad y de nuestra Patria, desde la trinchera de las letras.

\section{EGAÑA Y LOS PRINCIPIOS LIBERALES}

Vasco Castillo ha señalado que: “[...] la obra de Egaña [[...] ] cobra un nuevo sentido si lo enmarcamos dentro de la matriz del pensamiento republicano. Tal vez diríamos, cobra su real sentido [...]" ${ }^{1}$. Coincidimos con Castillo en que la obra de Egaña debe ser leída en clave republicana, entendida esta como el régimen de libertad interior y exterior de la Nación. Sin embargo, también añadiríamos la siguiente observación: la obra de Egaña también debe ser leída necesariamente en clave liberal. El republicanismo por sí solo no supone la existencia de un régimen liberal, pese a que son un buen complemento, y viceversa, el liberalismo no supone la existencia de un régimen republicano.

Es en este punto donde debemos detenernos para intentar presentar sucintamente de que liberalismo estamos hablando. Ello porque hoy en día podemos entender como liberal un concepto distinto al que entonces se tenía o se entendía

${ }^{1}$ Castillo, Vasco, La creación de la República. La filosofía pública en Chile 1810-1830 (Santiago de Chile, LOM Ediciones, 2009), pp. 40-41. 
por tal. El liberalismo al que aludimos entonces, se diferencia del liberalismo surgido luego de la segunda mitad del siglo XIX en Europa de la mano de pensadores, abogados y economistas como Karl Menger o Eugen von Bohm-Bawerk, precursores de la Escuela Austríaca y el capitalismo moderno. También se diferencia del erróneamente denominado neoliberalismo surgido en los Estados Unidos a propósito de la política del "new deal".

Muy por el contrario, el liberalismo de finales del siglo XVIII y comienzos del siglo XIX y que tratamos a continuación, tiene un contenido más bien político que económico ${ }^{2}$, y más jurídico que social. Esto porque el liberalismo surge como reacción no frente a un modelo económico centralista -ya veremos que el mercantilismo colonial no es sinónimo de esto último-, sino frente a un régimen político que pretendía absorber toda participación cualquier instancia de participación individual en la conducción de los asuntos públicos, del mismo modo que tampoco se trató de una ideología que buscaba un real transformación de la sociedad sino que a través de la Ley sentar las bases para una igualdad normativa.

En consecuencia, el concepto liberal que tendremos en mente cuando hagamos referencia a dicho concepto, será aquel que se nutre principalmente de la Ilustración francesa, florece principalmente con la Independencia Norteamericana, aprende de sus errores en la Revolución Francesa, y se traslada a América durante la Guerra de Independencia española. Es decir, nos referiremos principalmente a lo que hoy entendemos como "liberalismo gaditano".

En el caso de Egaña, el liberalismo queda de manifiesto a lo largo de toda su obra, manifestándose en la adopción e implementación de principios de raíz liberal. Nos enfocaremos para nuestro estudio, en el tratamiento que el autor realiza de algunos principios como la libertad, la igualdad, y la participación política, dejando para después el tratamiento de principios liberales de corte económico.

Sobre lo primero, debemos distinguir entre la libertad exterior e interior de la Nación. Por la primera nos referimos a la independencia de Chile respecto a la injerencia extranjera, mientras que por la segunda a la libertad individual de los ciudadanos. Respecto a aquella, el pensamiento de Egaña sufre ligeros cambios entre 1810 y 1820 . La explicación de ello es sencilla, y se explica por el cambio político entre una época y otra: de los últimos años de la colonia y la incertidumbre política de la Patria Vieja, a la Independencia definitiva lograda durante la Patria Nueva. Por lo mismo, en sus primeras obras veremos que la libertad política de Chile aún conserva lazos con la metrópoli, mientras que en la tercera década del siglo XIX no existirá referencia alguna a dichos vínculos. En cuanto a la libertad individual de los ciudadanos en cambio, no hay diferencias sustanciales entre ambos períodos. Tanto la obra de 1811 como las posteriores consagran la libertad del individuo y contemplan las garantías necesarias para asegurarla. Ejemplo de ello encontramos en el artículo 81 del "Proyecto de 1811", en el cual señala que "Desde la publicación de la Constitución ninguno nace esclavo en el territorio de la

${ }^{2}$ Jones, Stuart, Las variedades del liberalismo europeo en el siglo XIX: perspectivas británicas y francesas, en JAKSIC, Iván - POSADA, Eduardo, Liberalismo y poder. Latinoamérica en el siglo XIX (Santiago de Chile, Fondo de Cultura Económica, 2011), pp. 51 ss. 
república $[\ldots]$ "..3. Sin embargo la mejor manifestación de la libertad del ciudadano dice relación con el control de los abusos por parte del Estado. Para ello se establecían una serie de mecanismos que buscaba poner coto a la discrecionalidad de la administración. Y la forma de hacerlo, era mediante el sistema de contrapesos entre las distintas magistraturas. En este sentido Egaña se aparta de la concepción ilustrada de la separación de poderes, manifestándose expresamente en su contra. Sin embargo, el actuar del Estado quedaba restringido precisamente para asegurar la libertad individual. La Ilustración primera, con la cual Egaña explicaba razonadamente su "Proyecto de 1811 ", se abocaba precisamente al tema: “Cómo podrá asegurarse más bien la libertad pública y el vigor de la constitución contra las usurpaciones del gobierno [...]?”“4. Esto también explica el concepto de sujeción del Estado a la Ley, aspecto en el cual Juan Egaña fue enfático, siendo un tema recurrente en sus trabajos el contemplar frenos y mutuos pesos entre las magistraturas, así como la sujeción de las mismas a la estricta observancia de la Ley y el control de legalidad y constitucionalidad por parte de una magistratura contralora: "Yo juzgo que si se establece un poder moderante en la forma de nuestra censura, no existe peligro, ni de tirania, ni de odiosidad [...]"5.

En cuanto a la igualdad, debemos mencionar que esta se consagra a lo largo de toda su obra como constitucionalista, tanto en el "Proyecto de 1811", la carta de 1823, o el borrador de 1827. La igualdad supone, desde el punto de vista económico, la paridad de condiciones para lograr la consecución de un fin determinado. Por lo mismo no importa tanto la igualdad de facto como la igualdad de origen. En este sentido, Egaña contempla la posibilidad de que cualquier ciudadano pueda optar a los mismos cargos, y a lograr idéntica realización personal, sin distinguir entre clases o castas privilegiadas. Incluso la misma concesión de posibles privilegios, quedaba sujeto al mérito de cada persona. Por lo demás, Egaña se adelantaba a su tiempo prohibiendo la esclavitud en el país. Si bien no se trató de una derogación total de la práctica, se estableció que en Chile no nacían esclavos. En este sentido, el "Proyecto de 1811" hace eco de la "Ley de libertad de vientres" del mismo año. Finalmente, es necesario señalar que en sus obras se contempla una sociedad igualitaria ante la ley, donde no existen castas ni grupos privilegiados por nacimiento. La existencia de categorías como la de Ciudadano Benemérito no rompe con el mencionado principio, toda vez que esta institución quedaba abierta a cualquier ciudadano, que en base a su sólo mérito, se hiciere merecedor de aquella distinción, la cual por lo demás, consistía en un mero premio y no importaba una real concesión de privilegios.

Finalmente, en cuanto a la participación política, vemos que Egaña sigue la misma regla que mencionábamos en las líneas anteriores: no existían limitaciones de cuna en cuanto al acceso al ejercicio de los derechos políticos, si bien si existían limitaciones en consideración al mérito de la persona. De este modo, no cualquiera podía acceder a los cargos públicos o concurrir a sufragar, y ello dependía de la

\footnotetext{
${ }^{3}$ Sesiones de los Cuerpos Legislativos [en adelante SCL.], I, p. 219.

${ }^{4} S C L$., I, p. 243.

${ }^{5}$ SCL., I, Ilustración primera, p. 244.
} 
calidad del ciudadano en base a su mérito cívico, es decir, de los servicios que hubiere prestado a la Patria.

\section{EGAÑA Y LA PROPIEDAD PRIVADA}

Debemos comenzar mencionando que la propiedad privada se reconoce y protege en toda su obra constitucional. El “"Proyecto de 1811" " señalaba en su artículo que: "La Constitución asegura la propiedad $i$ el libre uso i disposición de los bienes, personas $i$ derechos de cada uno, siempre que no resulte daño a tercero, i que el hombre esté bajo dominio de si mismo i con perfecto uso de su razón”. Este artículo se situaba en la primera parte del Proyecto, justamente luego de tratar sobre la seguridad individual y antes de la libertad civil. Vemos entonces que la importancia que Egaña reconoce a la propiedad incluso en la prelación de tratamiento que da a las materias, es fundamental. Sin embargo, se reconocían ciertas limitaciones a la propiedad individual, tales como casos de necesidad pública como el uso de bienes particulares para la "defensa de la Patria" (artículo 19). Además se contemplaba la posibilidad de que el Estado pudiese expropiar un bien privado siempre contemplando una indemnización previa y justa según hubiese acordado el Tribunal de Censura. Esto se explica si tenemos en cuenta el espíritu corporativista que Egaña tenía de la sociedad precisamente por haberse formado en América colonial. A lo anterior debemos añadir que la facultad de uso de la propiedad quedaba limitada al dueño en tanto este abusaba de la misma. Es decir, no se podía usar de una cosa causando daños a un tercero. El domicilio personal se consideraba un lugar sagrado (artículo 16), al igual que la correspondencia y papeles particulares. Por ello eran considerados inviolables por parte de la autoridad, salvo que existiesen presunciones graves respecto de estos. Finalmente, la propiedad sobre la propia persona quedaba fuera del comercio humano, lo que se entiende dentro del contexto del Proyecto, que pretendía terminar con la esclavitud (artículo 81), estableciendo la libertad de todos los nacidos en Chile y conservando a los esclavos ya existentes en el territorio en una situación de suave domesticidad. Esta situación se mantenía precisamente porque Egaña contemplaba que los esclavos eran propiedad de sus dueños, y en consecuencia no se podía expropiar a estos sin una justa indemnización.

Distinto a la propiedad era la situación se los propietarios. Egaña veía en la propiedad una especie de mérito personal que colocaba a las personas en una mejor posición social en directa proporción a su patrimonio. El mismo autor confirma esta idea al señalar que "La lei sólo distingue en los ciudadanos las virtudes, los talentos $i$ los servicios", siendo la fortuna de cada persona el fruto de sus talentos. Por tanto, el régimen de Egaña tiene tanto de aristocrático como de plutocrático. Ejemplos de ello se encuentran a lo largo de todo el Proyecto. El artículo 10 establecía que las penas corporales privativas de libertad debían ser reemplazadas por una fianza suficiente si el afectado estaba en posición de rendirla, y otros mecanismos contemplados en el Proyecto se basaban precisamente en el patrimonio personal para establecer ciertos reconocimientos: el artículo 68 que establecía los requisitos para obtener el mérito cívico señalaba precisamente 
que quedaba en posición de obtenerlo todo aquel que "concurra con sus talentos, haberes o trabajo, a alguna obra pública o al alivio i felicidad de alguna clase de individuos miserables"; o también "[...] los que pusieren caudales respectivamente considerables en fondos públicos o compañias particulares, que se dirijan a fomentar la agricultura i la industria particular". Frente a una situación bélica, los propietarios contaban un representante ante la Junta de Administración de la Hacienda nacional, por tener precisamente un mayor interés en el devenir del país (artículo 169 ss.). Ejemplo de ello también se aprecia en las colonias militares, en las cuales la propiedad inmueble era utilizada precisamente como un incentivo a formar soldados-propietarios interesados en el acontecer público ${ }^{6}$.

En la Constitución de 1823, Egaña vuelve sobre los mismos principios ${ }^{7}$. Su artículo quinto señalaba que "las garantías constitucionales y las leyes protegen a todo individuo que reside en Chile”, artículo que establecía una función garantista por parte del estado respecto a los individuos, y que en consecuencia se traducía en la protección que se debía dar a los propietarios. El artículo 116 complementaba la norma antes citada, y establecía que: "El Poder Judicial protege los derechos individuales de acuerdo a las reglas siguientes"; y continúa señalando inmediatamente en el artículo 117 que: "A ninguno puede privarse de su propiedad, sino por necesidad pública, calificada por el Senado de notoriamente grave, y con previa indemnización”. No sólo el artículo es de gran contenido, sino la ubicación del mismo: la protección de la propiedad se trata como la primera de todos los derechos individuales, lo cual confirma la tesis que resalta el rol que jugaba la propiedad privada en el pensamiento de Egaña. En cuando a la norma propiamente tal, vemos que el lenguaje utilizado por el autor varía respecto al mismo precepto en su "Proyecto de 1811", pero conservando el mismo principio. Otra diferencia queda en evidencia con la protección de la propiedad, cuya garantía queda entregada al Poder Judicial, mientras que la expropiación debe ser acordada por el Senado, que en esta oportunidad cumplía prácticamente las mismas funciones que la Censura en el "Proyecto de 1811".

Lo anterior se reafirma en sus Cartas Pehuenches, obra contemporánea al proyecto que analizamos. En ellas Egaña señalaba que: "[...] el verdadero manantial de los fondos fiscales consiste principalmente en proteger la propiedad y la seguridad personal, cuya confianza desempeña la industria, y hace circular los caudales que con sus giros forman la riqueza del Erario."

En cuanto a la propiedad sobre la propia persona, la Carta de 1823 no contempla ninguna norma especial, aunque si se pronuncia expresamente en contra de la esclavitud en general: "En Chile no hay esclavos [...]" (artículo 8). Esto es importante, ya que a diferencia del proyecto anterior, Egaña consagra la libertad individual como una garantía universal para toda per-

\footnotetext{
${ }^{6}$ INFANTE, Javier, Juan Egaña y el Ejército de militares propietarios, en Revista Chilena de Historia y Geografia, 172 (Santiago de Chile, 2012), en prensas.

${ }^{7}$ Valencia, Luis, Anales de la República (2a Edición, Santiago de Chile, Editorial Andrés Bello, 1986), I, pp. 115-150.

${ }^{8}$ Egaña, Juan, Cartas pehuenches, en Feliú, Guillermo, Colección de antiguos periódicos chilenos (Santiago de Chile, Ediciones de la Biblioteca Nacional, 1958), XI, p. 23.
} 
sona presente en Chile y no sólo para los nacidos en el territorio nacional: “[...] el que pise si territorio por un día natural queda libre [...]". Este cambio de mentalidad se explica en el contexto legislativo de aquel período más que por un sincero cambio de opinión del autor: el mismo Congreso Constituyente que aprobó la Constitución de 1823, había aprobado con anterioridad la ley de libertad de todos los esclavos gracias al impulso del diputado José Miguel Infante. En la tramitación de aquella ley, Infante se había enfrentado precisamente con Mariano Egaña -hijo de Juan Egaña y entonces ministro del Interior de Ramón Freire-, quien sostenía que la abolición de la esclavitud no podía afectar los legítimos derechos de los propietarios de esclavos ${ }^{9}$.

Finalmente debemos mencionar que la calidad de propietario jugaba nuevamente un rol importante en la vida política de los ciudadanos. Para adquirir la calidad de ciudadano activo -es decir participante de la vida política del Estado- se establecía como primer requisito el poseer alguna propiedad inmueble que tuviese un valor no inferior a los doscientos pesos (artículo 11). También se establecía como requisito para acceder a ciertos cargos públicos, el ser dueño de una propiedad que tuviera cierto valor, el cual variaba de acuerdo a la importancia de la magistratura que se pretendía. Es decir, mientras mayor importancia tuviese la magistratura, mayor valor se exigía en la propiedad del aspirante a la misma. Citamos a modo de ejemplo los artículos 37, sobre requisitos para ser senador, y el artículo 61, que establecía los requisitos para ser electo consultor nacional. El primero de ellos establecía como requisito una propiedad inmueble cuyo valor no fuese inferior a los cinco mil pesos, mientras que para presentarse como candidato a consultor nacional era requisito una propiedad de a lo menos mil pesos.

Esta correlación entre patrimonio y poder establecida por Egaña obedece claramente al imaginario ilustrado ${ }^{10}$, el cual comprende -bajo la influencia protestante- que la fortuna de un individuo es el reflejo de sus talentos, y en consecuencia, su mejor capacidad para administrar y ejercer cargos de interés público. El autor profundiza esta postura en su Examen, en el cual manifiesta a propósito de la formación de las costumbres públicas y el mérito cívico que: "El derecho de ciudadanía en los que no son propietarios, está vinculado a ciertas acciones que forman la prosperidad o la moralidad nacional" ${ }^{11}$, o dicho de otro modo, aquellos que ya son propietarios no deben acreditar su mérito para ejercer la ciudadanía porque su mérito se contiene precisamente en dicha calidad. En una obra posterior, titulada Ocios Filosóficos en la Quinta de las Delicias, Egaña señalaría que "La enorme diversidad de fortunas es el origen de la mayor parte de

${ }^{9}$ SCL., VII, pp. 296 ss.

10 "Para los liberales, se trataba de un deber de confianza, una responsabilidad, para ejercerlo en nombre de la comunidad, y esta confianza debía entregársele a quienes demostraran ser, o pudiera suponerse que eran, competentes": JONES, Stuart, Las variedades del liberalismo, cit. (n. 2), p. 55.

${ }^{11}$ Egaña, Juan, Examen instructivo sobre la Constitución Política de Chile, en Feliú, Guillermo, Colección de algunos periódicos Chilenos (Santiago de Chile, Ediciones de la Biblioteca Nacional, 1966), XVII, p. 17. En la Ilustración II de su "Proyecto de 1811", Egaña señalaba que: "La aristocracia pone la administración en las manos de una clase de personas distinguidas $i$, por lo regular, sabias”. SCL., I, p. 246. 
los desórdenes y disgustos sociales [...] No es posible remediar absolutamente este mal, porque los hombres de más valor, entendimiento, o economía, siempre han de ser más poderosos; $y$ si se quieres establecer un pueblo de Espartanos, será preciso que hayan Ilotas, y costumbres bárbaras y atroces", para luego plantear como solución a dicho problema el establecimiento de una sociedad de propietarios agrícolas, ya que "[...] las costumbres sencillas, laboriosas, y pacificas, son amigas inseparables de la propiedad, de la ocupación, y de la igualdad." 12 .

El último intento constitucional de Juan Egaña tuvo lugar en 1827. En aquel proyecto, publicado en el tomo IV de sus Obras Completas, Egaña presenta una obra notablemente más resumida que sus obras anteriores: consta tan sólo de 27 artículos. En el artículo 26 del mismo, se señala: "La Constitución protege: la libertad civil; la seguridad individual; la propiedad; la igualdad legal y de contribuciones [...]"13. Vemos un cambio en el orden de prelación que el autor da a la protección de la propiedad, la cual queda en un tercer lugar luego de la libertad civil y la seguridad individual. Lamentablemente el autor no redactó una explicación de este proyecto, y de las obras políticas contemporáneas al mismo poco se puede desprender en orden a ilustrar la posible causa de este cambio. Sin embargo, podemos presumir que se trataría tan solo de un cambio accidental, influido por la redacción breve del articulado del proyecto.

\section{LibERTAD DE COMERCIO Y ROL ECONÓMICO DEL ESTADO EN EGAÑA}

Ya sabemos que Juan Egaña nació en Lima, centro neurálgico del Imperio Español en América del Sur, durante la segunda mitad del siglo XVIII. No debería extrañarnos entonces, que así como su pensamiento político, jurídico, filosófico o social, de la misma manera se viese influida su mentalidad económica debido a su formación en el imaginario del Régimen Colonial. En consecuencia, veremos que la corriente económica que sigue Egaña a lo largo de su obra será principalmente el mercantilismo español del siglo XVIII ${ }^{14}$. Si bien el presente trabajo no tiene por objeto tratar la historia del pensamiento económico, debemos intentar explicar de manera resumida que se entiende por mercantilismo, y que se entendía en aquel entonces.

El mercantilismo surge como una corriente económica durante el siglo XVI, principalmente en Francia e Inglaterra. En España recién se verán las primeras

${ }^{12}$ Egaña, Juan, Ocios filosóficos en la Quinta de las Delicias, en EL MISMO, Colección de algunos escritos políticos, morales, poéticos y filosóficos (Londres, Imprenta de Manuel Calero, 1829), IV, pp. 56 ss.

${ }^{13}$ Ibíd.

${ }^{14}$ Para entender el mercantilismo, véanse: RuIz, Julián - GARCíA, Cristina, Cargadores a Indias (Madrid, mapfre Ediciones, 1992); García-Baquero, Antonio, Cádiz y el Atlántico (1717-1778). El comercio colonial bajo el monopolio gaditano (Sevilla, Escuela de Estudios Hispanoamericanos del Ediciones del Consejo Superior de Investigaciones Científicas, 1976); HECKSCHER, Eli, La época mercantilista: historia de la organización y las ideas económicas desde el final de la Edad Media hasta la Sociedad Liberal, (México, Fondo de Cultura Económica, 1943); Perdices de Blas, Luis - ReEDER, John, El mercantilismo: política económica y Estado Nacional (Madrid, Editorial Síntesis, 1998). 
características de mercantilismo durante el siglo XVIII, principalmente debido al retraso con el cual las ideas del resto de Europa penetraban en la península, en gran medida debido al aislacionismo promovido por la Dinastía de los Austria. Sin embargo, tanto en Inglaterra como en Francia, el desarrollo del humanismo encontró un campo mucho más fértil para sembrar sus ideas, y con ello la implementación de nuevas políticas, incluyendo políticas económicas. Surge de esta forma el mercantilismo, como corriente que busca la acumulación de riquezas mediante un desarrollo comercial que se basa en un estricto control de la actividad económica por parte del Poder público. No debemos confundir esta vigilancia estatal con una directa participación de la Administración en la economía. Muy por el contrario, el mercantilismo es una corriente en la cual sus principales actores serán los privados - pequeños burgueses, comerciantes y precarios industriales-, quienes para el desarrollo de su actividad se valdrán del poder público. Es decir, se trata de una relación más bien simbiótica entre los privados y el poder público en torno a la actividad económica. El poder público veía fortalecida su posición gracias a la riqueza acumulada en el país ${ }^{15}$, y los comerciantes se valían de aquel poder para realizar sus negocios sin interferencias ${ }^{16}$. Ahora bien, es importante destacar que esta acumulación de riqueza no aludía necesariamente a la acumulación de dinero. El mercantilismo no confundía riqueza y dinero. Por el contrario, lo que se buscaba y entendía por riqueza era el crecimiento económico en per se, lo cual se traducía, como veremos, en la existencia de una balanza de pagos favorable ${ }^{17}$.

Como mencionábamos más arriba, se pretendía mediante el mercantilismo la acumulación de riquezas a nivel nacional. Esto es sin duda un concepto novedoso, ya que hasta entonces la economía era más bien local. Debido al reformismo político que tuvo lugar entonces - principalmente en la Francia absolutista- el Poder público buscaba terminar precisamente con todos aquellos residuos del régimen medieval, lo cual abarcaba desde terminar con los privilegios locales y aplicar una sola autoridad, un solo sistema político a todo el territorio controlado por un mismo poder. De ahí que el mercantilismo tenga como característica este rasgo nacionalista: se buscaba el crecimiento económico general, no local. En España esta unidad nacional no tuvo el mismo alcance que en las otras potencias de entonces. Basta recordar que la unificación Española recién se comenzó a consolidar con los "Decretos de Nueva Planta" luego del advenimiento borbónico, ya que antes España era más parecida a una comunidad de naciones bajo un único monarca que a un país unitario. Sin embargo, precisamente a raíz de la llegada de los borbones -y en consecuencia las ideas francesas-, la unidad política (y económica) de España comenzó lentamente a hacerse realidad. Ejemplos de ello encontramos en la supresión de las aduanas dentro del suelo peninsular, con algunas excepciones, o en el Reglamento de libertad de comercio de Carlos III.

Ahora bien, pese a estas diferencias en la implantación del mercantilismo entre España y los demás países europeos, lo cierto es que las características que ilustran esta corriente son iguales para todos, pese a que como veremos, en

\footnotetext{
${ }^{15}$ Ruiz, Julián - García, Cristina, Cargadores a Indias, cit. (n. 14), p. 42.

${ }^{16}$ García-Baquero, Antonio, Cádiz y el Atlántico, cit. (n. 14), p. 59.

${ }^{17}$ Ibíd., p. 63.
} 
España se generó cierto rechazo. Estos son la acumulación de riquezas, la existencia de una balanza comercial favorable, y la intervención del poder público para la consecución de ello. La relación que existe entre estas tres características del mercantilismo es evidente: una política comercial basada en el férreo control del comercio internacional aseguraba la acumulación de riquezas en el país. Y la forma de lograrlo era principalmente mediante la política fiscal sobre el comercio internacional: se promovía la importación de materias primas, al mismo tiempo en que se incentivaba la exportación de productos manufacturados de mayor valor, y a la inversa, se gravaba con altos aranceles el ingreso de bienes manufacturados, así como la exportación de materias primas. De esta forma, los comerciantes peninsulares tenían asegurado, con la ayuda del poder público, un mercado cautivo para realizar sus negocios ${ }^{18}$. No obstante, el monopolio mercantil pretendido no funcionó de la forma deseada, y el mercantilismo planeado en la Corte durante la primera mitad del siglo XVIII se vio alterado por medidas reformistas durante la segunda mitad de la centuria.

La realidad americana de Juan Egaña no escapaba a esta realidad. En consecuencia, el autor se formó en un ambiente reformista que buscaba hacer más eficientes las rentas reales mediante instituciones más bien "liberales" que se encuadraban precisamente dentro del modelo mercantilista: el Reglamento de libre comercio entre España e Indias de 1778, el establecimiento de los "navíos de registro", la reforma del sistema comercial mediante la creación de los consulados, entre otras ${ }^{19}$. Todas estas medidas tendían, como dijimos, a consolidar el modelo mercantilista en las Indias, aunque sin que lograse totalmente el efecto buscado. Muy por el contrario, cuando estas medidas fueron implementadas, especialmente en la alejada Capitanía General de Chile, la situación comercial ya se encontraba prácticamente fuera del control de las autoridades indianas ${ }^{20}$, debido en gran medida al contrabando existente, el cual abastecía con abundancia de manufacturas y todo tipo de mercaderías extranjeras.

La caída del régimen indiano dio paso a nuevos países que debían organizar sus precarias economías. Salvo los casos de México y Perú -y quizá alguna excepción como Buenos Aires durante los últimos años del Virreinato-, verdaderos núcleos urbanos y económicos en América, los demás territorios no tenían economías de un desarrollo importante. Por el contrario, podríamos concluir que se encontraban en una situación de franca precariedad comercial ${ }^{21}$. Chile se encontraba en esta última situación. Se trataba de un territorio agrícola, con escases de industrias, cuya

\footnotetext{
${ }^{18}$ Ruiz, Julián - García, Cristina, Cargadores a Indias, cit. (n. 15), p. 43.

${ }^{19}$ Sobre las reformas borbónicas, véase: NAVARRO, Luis, El reformismo borbónico: proyectos $y$ realidades, en BARRIOS, Feliciano, El Gobierno de un Mundo: virreinatos y audiencias en la América hispánica, (Cuenca, Ediciones de la Universidad de Castilla-La Mancha, 2004).

${ }^{20}$ VIllalobos, Sergio, El comercio extranjero a fines de la dominación española, en Journal of Inter-American Studies, 4 (Miami, 1962), p. 533; 1965, p. 24; Villalobos, Sergio, El comercio y la crisis colonial (Santiago de Chile, Ediciones de la Universidad de Chile, 1968), p. 132 ss.

${ }^{21}$ Véase: JarA, Álvaro, El Imperio español en América. Una historia económica (Santiago de Chile, Editorial Sudamericana y Random House Mondatori, 2011).
} 
economía se sostenía principalmente en la agricultura, la minería, y los negocios de algunos pocos comerciantes.

En consecuencia, Egaña enfrentó el problema desde su propia experiencia: el modelo mercantilista. Sin embargo, no debemos suponer que las ideas de Egaña en materia económica estaban carentes de contradicciones. Por el contrario, al igual que en las otras aristas de su pensamiento, la contraposición del imaginario colonial hará frente a las ideas ilustradas que el autor había recogido en su amplia biblioteca. Por ejemplo, sabemos que el autor poseía una copia de The Wealth of Nations, de Adam Smith ${ }^{22}$, autor que nos consta fue leído por Egaña gracias a citas que el mismo manifiesta en su obra. En efecto, en sus Ilustraciones al "Proyecto de 1811", el autor no duda en señalar que: "Los legisladores deberán tener muy presentes los preciosos principios de Smith para arreglar las contribuciones", citando expresamente a pié de página la obra mencionada ${ }^{23}$. Sin embargo la influencia de Smith no siempre es manifiesta, sino que aflora entre algunos pasajes de la obra de Egaña. Por ejemplo, en la Noche cuarta de sus Ocios Filosóficos, el autor señala que: "Un Estado es una familia en grande; y las economías que no puede verificar el padre de familias en su casa, siempre serán ilusorias en una república”, comparación que es usada de la misma forma por $\mathrm{Smith}^{24}$.

Las lecturas de Egaña sobre temas relacionados con la Economía, el comercio o el Derecho mercantil no se agotaban obviamente en Smith, y gracias al importante trabajo realizado por el profesor Carlos Salinas, contamos con un inventario detallado de las obras que han de haber influido en el pensamiento económico del autor ${ }^{25}$. Entre las materias que encontramos en la biblioteca de Mariano Egaña, muchos de los cuales fueron heredados de su padre, contamos tratados de Economía política -Jean-Baptiste Say, David Ricardo, Antonio Genovesi, John Stuart Mill, entre otros-, Derecho marítimo y mercantil, o libertad de los mares. También se encuentran en su biblioteca obras de Jeremy Bentham, aunque solo referidas a temas jurídicos y no económicos.

Asimismo en su discurso titulado Oración inangural para la apertura de los estudios de la Real Universidad de San Felipe en el año de $1804^{26}$, el autor señala, luego de mencionar a grandes pensadores del Humanismo y el Racionalismo como Galileo, Newton o Leibniz, que: "De estos hemos recibido las ciencias en un grado de perfección digno de lisonjear al género humano, y aún en nuestros días florecen hombres tan grandes que nada podemos envidiar a los siglos XVI y XVII [...] ¿[que sería] El entendimiento humano y la política económica no vivieran gloriosos entre Condillac, Ustáriz, Necker y Genovesi? [...]".

Pese a la influencia que los autores mencionados puedan haber tenido en su

${ }^{22}$ Salinas, Carlos, La biblioteca de don Mariano Egaña, con especial referencia a sus libros de Derecho, en Revista de Estudios Histórico-Jurídicos, 7 (Valparaíso, 1982), p. 510.

${ }^{23}$ SCL., I, p. 247.

${ }^{24}$ Friedman, Milton, Libertad de elegir (traducción al castellano de la $1^{a}$ edición en inglés, Barcelona, Ediciones Folio, 1997), p. 63.

${ }^{25}$ Salinas, Carlos, La biblioteca de don Mariano Egaña, cit. (n. 22).

${ }^{26}$ El discurso completo se encuentra en SILVA, Raúl, Juan Egaña. Escritos inéditos y dispersos (Santiago de Chile, Imprenta Universitaria, 1949), pp. 10 ss. 
pensamiento, lo cierto es que su obra se presenta llena de elementos tanto mercantilistas como del pre capitalismo.

Uno de los primeros ejemplos de ello lo encontramos en una "Memoria" que Egaña presentó al Capitán General de Chile, conde de la Conquista, en el mes de agosto de $1810^{27}$, conocido entre los historiadores como "Plan de Gobierno"28. En ella el autor trata una amplia variedad de temas, incluyendo ciertas reformas al comercio colonial. Curiosamente, señala ciertos principios de los cuales más tarde renegaría en más de una oportunidad. Ejemplo de ello encontramos cuando Egaña presenta la necesidad de contar con una marina mercantil propia, cuya iniciativa fuese privada, contando con el apoyo del Tribunal del Consulado. Pese a esta idea, Egaña en general se opondrá a la creación de marinas mercantes o escuadras de guerra en obras posteriores ${ }^{29}$. Esta contradicción se explica por el contexto de la obra que acabamos de citar, la cual, a diferencia de sus obras posteriores, se traba de una memoria presentada a la autoridad colonial, dentro del contexto del comercio colonial indiano. Incluso en este caso, la idea de contar con naves propias no era una extravagancia propia de Egaña, sino que otros comerciantes chilenos ya habían contemplado la idea con varios años de antelación ${ }^{30}$.

Sin embargo, en esa misma "Memoria" el autor insistirá en la política agraria que debía fomentarse en Chile: "Este país es agricultor, el Comercio le facilitaría la extracción, y la población el consumo interior". Esta frase quizá sea el mejor reflejo del pensamiento económico de Egaña ${ }^{31}$. Vemos que la mentalidad mercantilista lo impulsaba a pensar en torno a un imaginario colonial, en al cual el país debía exportar productos de bajo valor (principalmente alimentos), e importar manufacturas para el consumo interno. Desde una perspectiva económica, su mirada era francamente nociva para la economía nacional, ya que ella repercutiría necesariamente en una balanza de pagos negativa. Ello se explica, reitero, por la mentalidad colonial del autor, quien posiblemente tenía conciencia del status colonial de nuestro territorio en cuanto provincia sirviente de la Metrópoli.

En su "Proyecto de 1811", Egaña volvió a tratar el tema del Comercio en el país. En el artículo 155 de dicha obra, se establece un Consejo de Economía Pública. Este tenía como funciones la "inspección i dirección del comercio, industria, agricultura, policía, navegación mercantil, oficios, minas, aguas, pesca, caminos,

${ }^{27}$ Archivo Nacional, "Varios", vol. 800 y reproducido íntegramente en MATTA, Enrique - Feliú, Guillermo (compiladores), Colección de historiadores y documentos relativos a la Independencia de Chile (Santiago de Chile, Imprenta Cervantes, 1911), XIX, pp. 97-109.

${ }^{28}$ Silva, Raúl, Egaña en la Patria Vieja 1810-1814 (Santiago de Chile, Editorial Andrés Bello, 1959), pp. 47 ss.

${ }^{29}$ INFANTE, Javier, Juan Egaña y el Ejército de militares propietarios, cit. (n. 6).

${ }^{30}$ Villalobos, Sergio, El comercio extranjero a fines de la dominación española, cit. (n. 20), pp. 537 ss.

${ }^{31}$ En el Examen de 1823, Egaña señalaba que: "Hay dos especies de comercio nacional: uno sedentario y otro ambulatorio o de tráfico [...]. Casi todas las naciones de Europa son traficantes, siendo la principal Inglaterra. Muchas de la Asia son manufactureras y todas sedentarias, siendo la China la principal [...]. Seguramente que la Inglaterra no tratará de competir ni con la agricultura China ni con las obras clásicas y prodigiosas de sus canales, allanamientos de terrenos, gran muralla, etc.”: SCL., VIII, p. 50. 
canales, examen de terrenos, productos minerales, bosques, indagaciones de aritmética, política $i$ aplicación de sus resultados a la policía i objetos gubernativos; $i$, en fin, cuanto pertenezca a la economía, policía y adelantamiento industrial, rural $i$ mercantil de la república" ${ }^{2}$. Se compondría de seis directores y un secretario, quienes debían sesionar diariamente e impulsar la pro actividad del Consejo. Dos directores quedarían encargados de visitas en el territorio nacional, de modo de fomentar la actividad económica en el mismo. Otros dos se deberían ocupar del funcionamiento interno del Consejo, y los dos restantes tendrían la especial función de "viajantes", quedando encomendados de viajar al extranjero para introducir en Chile nuevas técnicas y mecanismos de producción. Estos directores viajantes durarían diez años en sus funciones: el primero habría de ser destinado a las visitas por el territorio nacional, los cinco siguientes a viajes por el extranjero, y los cuatro restantes a la introducción y aplicación de los conocimientos adquiridos en el extranjero en la economía nacional. Los directores que no fuesen viajantes, durarían cinco años en sus funciones. El Consejo también cumpliría funciones de tribunal de alzada en materias comerciales (artículo 159). Es decir, habría de tener la misma función que el Tribunal del Consulado, pero en segunda instancia. Esto se debe a que el "Proyecto de 1811" no había sido concebido como un intento político independiente de la Metrópoli, sino que en un intento por organizar una provincia colonial. En consecuencia muchas de las magistraturas coloniales conservaban su vigencia. El texto del Proyecto alude siempre al concepto de reino, y el propio Egaña, cuando explica el modo de sufragar los gastos de todas las nuevas magistraturas contempladas en su obra, señala que: "todos conocen que una colonia no tiene los gastos de un pueblo independiente, como tampoco sus ventajas i proporciones. Para los objetos de soberanía, sólo hemos puesto dos magistraturas pagadas [...]. El [Consejo] de economía política, que es una reunión del consulado, minería i otros ramos, ofrece ahorros".

En cuanto al fomento del comercio, la Ilustración $V$ pone de manifiesto nuevamente la concepción agraria de Egaña, al mismo tiempo en el que vemos como desecha la idea de contar con una marina mercante, como había planteado un año antes en su "Plan de Gobierno": "Nos hemos contraído a exaltar la industria y la agricultura" 33 . La explicación de esta preferencia, a la vez que el rechazo a la existencia de una marina mercante, radicaba según el autor, en que "la localidad de este país a los extremos de la tierra no permite un arrieraje y tráfico útil [...] ", para luego agregar que "una marina comerciante excita el genio de ambición, conquista $i$ lujo; destruye las costumbres $i$ ocasiona celos, que finalizan en guerras.". Vemos entonces que no se trata de que Egaña desconfiara per se del comercio internacional, sino que de la existencia de una marina mercante nacional. En sus Ocios filosóficos insistirá en la misma idea: "Un pueblo que puede subsistir de su agricultura, no debe ser navegante, sino agricultor y manufacturero" ${ }^{34}$. Sin embargo, ello se trata de un error de concepto, como veremos más adelante al tratar las medidas proteccionistas contempladas por el autor.

\footnotetext{
${ }^{32}$ SCL., I. p. 227.

${ }^{33}$ SCL., I. p. 248.

${ }^{34}$ Egaña, Juan, Ocios filosóficos en la Quinta de las Delicias, cit. (n. 12), p. 61.
} 
En la Constitución de 1823, el autor sigue en la misma línea, reproduciendo casi de manera íntegra los artículos del Proyecto. La única diferencia de relevancia radica en cambio de nombre de la magistratura encargada, de Consejo a Dirección de Economía Nacional ${ }^{35}$. Sin embargo, a diferencia del Proyecto, en esta oportunidad Egaña sí explicó el razonamiento que subyace a dicha magistratura, en su Examen instructivo.

El argumento de fondo para establecer esta Dirección, radicaba en las ventajas y ahorros que presentaba al Gobierno. Por una parte, según el autor, se lograba contar con una magistratura especializada en el fomento económico, que prestaba funciones en el fomento del comercio, las obras públicas, entre otras. Y por otra parte, al contar con la Dirección se evitaba la necesidad de contar con multiplicidad de magistraturas distintas que si ocasionaban mayores gastos al erario, tales como los superintendentes, el Consulado o el Tribunal de Minería, magistraturas cuyas funciones quedaban incorporadas en la Dirección. Sobre los primeros, el autor probablemente tuvo a la vista los magros resultados de las empresas y fábricas reales del régimen colonial, como la Compañía Gipuzcoana en Venezuela o la Real Fábrica de Tabacos en Sevilla: "[...] poner un Superintendente muy pagado para cada empresa y aniquilar el erario con gastos aventurados [...]"36.

Fuera de sus obras de carácter constitucional, también podemos encontrar variadas referencias a su pensamiento económico, tal como ya pudimos apreciar en su "Memoria" de 1810. En sus Ocios filosóficos el autor vuelve a tratar el tema del comercio, poniendo de manifiesto sus ideas de fondo sobre el tema.

Comienza su Noche cuarta $^{37}$, tratando precisamente la organización social, y dentro de ella se desarrolla un interesante discurso económico. El primer problema que el autor aborda, dice relación con las diferencias patrimoniales entre los individuos: "La enorme diversidad de fortunas es el origen de la mayor parte de los desórdenes y disgustos sociales". Como vimos al comenzar el presente trabajo, estas diferencias precisamente justificaban la decisión del autor, en torno a considerar la calidad activa o pasiva de los individuos en relación con la actividad política. Por lo mismo, no es de extrañar que el autor, teniendo en cuenta esta disparidad en las fortunas de los ciudadanos, lo haya considerado como un elemento determinante en la posición social que a cada uno le correspondía, incluso para los pensadores de la época. Por lo demás, el liberalismo político del autor bebía precisamente de la vertiente política de dicha corriente, y el liberalismo en ningún caso se presentó -al menos entonces- como una corriente democrática ${ }^{38}$. Como fuere, dicha diferencia existente era notada por el autor, quien veía como única solución posible contra ella el evitar una población numerosa, objetivo que se cumpliría si se mantenía una economía principalmente agraria basada en la explotación por pequeños propietarios. La referencia a un bajo número demográfico se explica

${ }^{35}$ SCL., I, p. 655.

${ }^{36}$ Egaña, Juan, Examen instructivo sobre la Constitución Política de Chile, en Feliú, Guillermo, cit. (n. 11), p. 32.

${ }^{37}$ Egaña, Juan, Ocios filosóficos en la Quinta de las Delicias, en El Mismo, cit. (n. 34), pp. 55 ss.

${ }^{38}$ JONES, Stuart, Las variedades del liberalismo, cit. (n. 10), p. 54. 
por la correlación que existía en el pensamiento de Egaña, entre una población reducida de propietarios y la moralidad de la misma: "Alli se encontrará amor al orden público, sumisión a las leyes, y felicidad doméstica; pues las costumbres sencillas, laboriosas, y pacificas, son amigas inseparables de la propiedad, de la ocupación, y de la igualdad"39.

Estos productores agrícolas y aquellos pequeños manufactureros, tendrían una libertad absoluta para comerciar, quedando las aduanas encargadas únicamente de fiscalizar las importaciones. Es decir, Egaña establecía una política arancelaria proteccionista que buscaba consolidar precisamente el modelo mercantilista aplicado a una economía agraria: exportar sin trabas tanto productos agrícolas, manufacturados o materias primas como minerales, e imponer altas tasas a las importación de semejantes productos. Todo ello obedece al presupuesto mercantilista de fomentar el mercado interno mediante una protección de la producción local en vistas de obtener una balanza de pagos favorable. Sin embargo, Egaña incurría en un error de supuestos: el mercantilismo funciona si el sistema de aranceles favorece la importación de materias primas y desincentiva la de productos manufacturados (de mayor valor agregado), y no a la inversa, incentivando la exportación de materias primas y evitando el ingreso la de productos manufacturados. Esto se apoya en otro pasaje del autor, contenido en las Ilustraciones, donde señala que "[...] su fertilidad [se refiere a Chile] proporciona una industria baratísima, que debe atraer mayor concurrencia que la India, i en donde sea proveida de todos los tesoros e industrias de otros paises sin peligro de guerras [...]" ${ }^{40}$. El error radica en que la política de Egaña consiste precisamente en exportar materias primas y algunas manufacturas, y a su vez proveerse se productos más elaborados mediante importaciones gravadas. Es decir, vender barato y comprar caro: "Este pueblo debe vender a bajo precio, para que todos vengan a comprarle [...]” ${ }^{\prime 1}$. En consecuencia, el modelo comercial de Egaña estaba tan errado como su concepción naval del país ${ }^{42}$.

\section{EgAÑA Y LOS IMPUESTOS}

Antes de presentar el debemos señalar que el pensamiento del autor sobre el tema no se ha tratado de manera sistemática en alguna de sus obras de carácter constitucional, o bien en las de carácter monográfico. Por el contrario, encontramos normas de carácter tributario dispersas en distintas partes de su obra, por ejemplo en el tratamiento de situaciones militares, educacionales u otras.

La política tributaria de Juan Egaña se encuadra dentro del modelo económico mercantilista. La primera alusión al tema tributario se encuentra en su "Memo-

${ }^{39}$ Egaña, Juan, Ocios filosóficos en la Quinta de las Delicias, en El Mismo, cit. (n. 37), p. 56 s. En esta misma obra, p. 63, el autor señalaba a este respecto que: "Jamás debe procurarse demasiada población en ningún país. Un número suficiente de brazos abarata y facilita los alimentos: la escasez de hombres, o su excesivo número los encarece [...]".

${ }^{40}$ SCL., I, Ilustración V, p. 248.

${ }^{41}$ Egaña, Juan, Ocios filosóficos en la Quinta de las Delicias, en El Mismo, cit. (n. 39), p. 61.

${ }^{42}$ INFANTE, Javier, Juan Egaña y el Ejército de militares propietarios, cit. (n. 29). 
ria” de 1810. En aquella oportunidad, Egaña trata el tema de las contribuciones precisamente a propósito de la agricultura. Pretendía establecer una triple alcabala sobre las compras de predios por parte de aquellos propietarios que ya tuviesen un paño de tierra considerable, para así "evitar que grandes masas queden incultas en pocas manos" " . Debemos notar que Egaña concibe la política tributaria como una herramienta de la cual valerse para incentivar o desincentivar determinadas conductas. Esto queda de manifiesto en la Ilustración $I X$, en la cual el autor señala los vicios que conlleva el consumo de "licores fuertes", vicio que por lo mismo debe ser destruido. En atención de ello, el autor siguiere, entre varias medidas, "gravisimos derechos al aguardiente de consumo interior, $i$ absoluta relevación a su exportación" $"$.

Otra de las constantes que veremos en el tratamiento que el autor da a la materia, es la aversión al abultamiento del gasto público como producto de la política tributaria, así como la constante referencia que el autor hace a las palas prácticas públicas: el odio a la burocracia.

El "Proyecto de 1811" contenía una serie de disposiciones tributarias distribuidas a lo largo de su articulado. El primero de ellos es el artículo 21, ubicado en el título que el autor dedica a la consagración del derecho de propiedad. En él se señala: "La lei no puede establecer contribuciones sino para utilidad pública". Esta norma es clave para entender el pensamiento de Juan Egaña sobre la materia, toda vez que será una constante en su obra el evitar el pago de contribuciones, salvo en casos de verdadera necesidad. Uno de esos casos calificados era por ejemplo el caso de guerra, evento ante el cual "[...] los habitantes formarán un fondo extraordinario [...]” (artículo 168). Este artículo es extensamente explicado en las Ilustraciones, fundamentándose dicho fondo extraordinario en evitar contraer una deuda nacional frente a casos fortuitos ${ }^{45}$. Según Egaña -citando a Hume, Genovesi, Price y Montesquieu-, "[...] un Estado bien gobernado debe poner por primer artículo de sus gastos una suma arreglada para los costos fortuitos [...]" ${ }^{46}$. No obstante, el autor estaba consciente de lo difícil que resulta una recaudación especial en tiempos de conmoción, y por lo mismo contemplaba la posibilidad de emitir bonos estatales durante la guerra (artículo 171).

En la misma medida, la otra cara de dicha política consistía en el uso eficiente que debía hacerse de los fondos fiscales, evitando la burocracia y la corrupción. Una alusión a ello lo encontramos en la creación de dos plazas de Contadores

${ }^{43}$ Archivo Nacional, "Varios", vol. 800.

${ }^{44}$ SCL., I, p. 251. Esta idea se mantiene vigente en el pensamiento de Egaña en 1819 y 1820, cuando en la última de las Cartas pehuenches, el autor señalaba: "Prohibir absolutamente la entrada de aguardientes extranjeros y relevar de derechos de extracción de los nuestros". EGAÑA, Juan, Cartas pehuenches, en Feliú, Guillermo, cit. (n. 8), p. 52.

${ }^{45}$ También en sus Ocios filosóficos el autor es categórico sobre este punto: "Mejor es doblar las contribuciones en un conflicto, que tomar empréstitos”. EGAÑA, Juan, Ocios filosóficos en la Quinta de las Delicias, en El Mismo, cit. (n. 41), p. 58.

${ }^{46}$ SCL., I, Ilustración IV, p. 247. En las Cartas Pehuenches, el autor confirma la idea al señalar que "[...] en una revolución, y en una administración nueva existen infinitos desórdenes, cuyo remedio debe formar la primera partida de nuestros fondos": EGAN̄A, Juan, Cartas Pehuenches, en Feliú, Guillermo, cit. (n. 44), p. 23. 
Mayores, quienes debían llevar una "[...] superintendencia activa, eficaz e infatigable sobre todos los ramos públicos y fiscales. Son responsables de todos sus desórdenes i falta de economía [...]" (artículo 153). Resulta evidente que la inspiración de estas magistraturas se encontraba en el Régimen Colonial ${ }^{47}$. En la Carta tercera de sus Cartas pehuenches, Egaña señalaba que: "La exhortación más patética y eficaz para conducir al pueblo a los mayores sacrificios, es hacerle conocer la dedicación que ponen sus Magistrados en la economía y útil consumo de las rentas públicas [...]”, para luego señalar que "[...] la mitad de los beneficios sociales que pudieran establecerse necesitan más bien de genio, actividad y deseo de felicidad pública, que de grandes erogaciones $[\ldots]]^{\prime 48}$.

Finalmente, la proporcionalidad de los tributos también queda en evidencia a lo largo de su obra. El ya mencionado artículo 168, señalaba que en caso de fijarse una contribución extraordinaria por causa de guerra, debía exigirse la conformación del mismo de acuerdo al principio de la proporcionalidad. Se encomendaba esta función a los prefectos e inspectores comunales, quienes debían llevar a cabo su función "[...] perjudicando lo menos posible al transporte i la subsistencia de primera necesidad [...]" buscando siempre el menor impacto en la comunidad: "[...] repartirán el gravamen con el menor perjuicio posible [...]" (artículo 180). En este mismo sentido se encuadraba el artículo 193, el cual establece como requisito para formar Juntas Cívicas Generales en una ciudad o villa ${ }^{49}$, que frente a cualquier obra pública que estableciera un gran avance en la localidad, y cuyo costo hubiese sido financiado al menos en un cincuenta por ciento por el Erario público, debían concurrir los vecinos con el saldo restante. De no hacerlo, se les privaba de la facultad de conformar aquellas Juntas Cívicas.

En la Constitución de 1823, los principios ya enunciados serán nuevamente recogidos. El artículo 7, que consagraba la igualdad ante la ley, señalaba asimismo que: "todos contribuyen a las cargas del Estado en proporción de sus haberes [...]". Estos eran establecidos por el Senado, que tenía la facultad exclusiva de aprobar o suprimir contribuciones, así como las partidas presupuestarias presentadas por el Gobierno. También quedaba encargado el Senado de repartir las contribuciones entre los distintos departamentos del territorio (artículo 39). El artículo 236 confirmaba dicha facultad al señalar que "Sólo el Cuerpo Legislativo impone contribuciones directas o indirectas". El cobro de los impuestos a nivel de los departamentos quedaba encargado a los prefectos y sus inspectores (artículo $202 \mathrm{~N}^{\circ}$ 3), y a nivel municipal se encargaba a los regidores (artículo $221 \mathrm{~N}^{\circ} 8$ ). Para velar por el buen recaudo de las contribuciones y su correcta aplicación de acuerdo a las partidas presupuestarias, se establecía una Inspección General de Rentas Fiscales,

\footnotetext{
${ }^{47}$ Véase el libro II, título $11^{\circ}$ y el libro VIII, título $1^{\circ}$ de la Recopilación de las Leyes de los Reynos de las Indias.

${ }^{48}$ Esta idea es nuevamente considerada en la Carta sexta, donde el autor señala: "Acaso la mitad de los beneficios sociales interiores [...] exigen más bien genio y actividad, que dinero fiscal [...]”: Egaña, Juan, Cartas Pehuenches, en Feliú, Guillermo, cit. (n. 46), pp. 23 y 41.

${ }^{49}$ Las Juntas Cívicas Generales eran corporaciones representativas que tenían por único objeto el elegir a los funcionarios que la Constitución establecía, a diferencia de la Junta Cívica Gobernativa, que actuaba el proceso legislativo.
} 
la cual quedaba encabezada por dos Inspectores, con similares atribuciones a los Contadores Mayores del "Proyecto de 1811" .

Finalmente, en sus Ocios filosóficos el autor expone una teoría bastante peregrina, que no desarrolló en ninguna otra de sus obras: "En todos los ramos que sea posible, deben pagarse las contribuciones públicas en especie. Esta recaudación alivia al contribuyente, y asegura al fisco, porque se da lo que realmente se tiene" 50 . Lamentablemente no fundamenta esta peculiar medida, aunque resalta a la vista los grandes inconvenientes que hubiese tenido la implementación de semejante política. Sin embargo, en una obra anterior, el autor explica el objeto de recibir este tipo de contribuciones: "[...] que el Estado, con sus presas de mar, secuestros, contribuciones en especie, etc., formase un gran almacén, donde a precios corrientes, $y$ con vales voluntarios, buenas cuentas puedan ocurrir sus acreedores a tomar los que necesiten en abono de sus créditos y salarios" ${ }^{51}$.

\section{CONClusiones}

Queda en evidencia que el pensamiento de Juan Egaña en materia económica se encuadra dentro de la corriente mercantilista. Difícil hubiese sido esperar lo contrario, considerando el pensamiento, si bien no estatista, quizá dirigista del autor. Si bien el presente trabajo no pretende explicar el concepto de virtud cívica, moralidad nacional, o la correlación que existía entre ley y costumbre en el pensamiento de Egaña, temas que han sido tratados en otras obras ${ }^{52}$, sí pretendemos resaltar que la economía no quedaba lejos de la mano firme del Gobierno que Egaña pretendía implantar. La economía, al igual que las leyes, la educación o la religión, constituían una de las tantas herramientas mediante las cuales el autor buscaba la consolidación de una sociedad católica ilustrada, basada en la unidad y uniformidad nacional mediante la religión y la educación, virtuosa mediante leyes que se convertían en costumbres, pacífica a través de colonias de militares propietarios, y próspera -más no ostentosa ni viciosa- mediante una economía rural, agraria o precariamente manufacturera.

Del mismo modo en que la religión, la educación y la legislatura debían promover las virtudes clásicas que Egaña consideraba adecuadas para la nueva Nación, la economía debía servir como un escudo de protección contra la corrupción extranjera, ayudando a mantener aislado al país de influjos e ideas extrañas a su constitución histórica.

\footnotetext{
${ }^{50}$ Egaña, Juan, Ocios filosóficos en la Quinta de las Delicias, en El Mismo, cit. (n. 45), p. 57.

${ }^{51}$ EgaÑa, Juan, Cartas pehuenches, en Feliú, Guillermo, cit. (n. 48), p. 43.

${ }^{52}$ Véanse: Infante, Javier, Juan Egaña y el Ejército de militares propietarios, cit. (n. 42); Infante, Javier, El Proyecto de Código Moral de don Juan Egaña, en Revista Bicentenario, 11 (Santiago de Chile, 2012); Castillo, Vasco, La Creación de la República, cit. (n. 1), pp. Y-Z; Castillo, Vasco - RuIZ, Carlos, El pensamiento republicano en Chile: el caso de Juan Egaña, en Revista de Ciencia Politica, 21 (Santiago de Chile, 2001), pp. 25-40.
} 


\section{BiBLIOGRAFÍA}

Castillo, Vasco - Ruiz, Carlos, El pensamiento republicano en Chile: el caso de Juan Egaña, en Revista de Ciencia Política, 21 (Santiago de Chile, 2001).

Castillo, Vasco, La creación de la República. La filosofía pública en Chile 1810-1830 (Santiago de Chile, LOM Ediciones, 2009).

Egaña, Juan, Cartas pehuenches, en Feliú, Guillermo, Colección de antiguos periódicos chilenos (Santiago de Chile, Ediciones de la Biblioteca Nacional, 1958), XI.

Egaña, Juan, Examen instructivo sobre la Constitución Política de Chile, en Feliú, Guillermo, Colección de algunos periódicos Chilenos (Santiago de Chile, Ediciones de la Biblioteca Nacional, 1966), XVII.

Egaña, Juan, Ocios filosóficos en la Quinta de las Delicias, en El mismo, Colección de algunos escritos politicos, morales, poéticos y filosóficos (Londres, Imprenta de Manuel Calero, 1829), IV.

Friedman, Milton, Libertad de elegir (traducción al castellano de la $1^{\text {a }}$ edición en inglés, Barcelona, Ediciones Folio, 1997).

García-Baquero, Antonio, Cádiz y el Atlántico (1717-1778). El comercio colonial bajo el monopolio gaditano (Sevilla, Escuela de Estudios Hispanoamericanos del Ediciones del Consejo Superior de Investigaciones Científicas, 1976).

HECKSCHER, Eli, La época mercantilista: historia de la organización y las ideas económicas desde el final de la Edad Media hasta la Sociedad Liberal, (México, Fondo de Cultura Económica, 1943).

Infante, Javier, El Proyecto de Código Moral de don Juan Egaña, en Revista Bicentenario, 11 (Santiago de Chile, 2012),

INFANTE, Javier, Juan Egaña y el Ejército de militares propietarios, en Revista Chilena de Historia y Geografia, 172 (Santiago de Chile, 2012), en prensas.

JARA, Álvaro, El Imperio español en América. Una historia económica (Santiago de Chile, Editorial Sudamericana y Random House Mondatori, 2011).

JONES, Stuart, Las variedades del liberalismo europeo en el siglo XIX: perspectivas británicas $y$ francesas, en JAKSIC, Iván - POSADA, Eduardo, Liberalismo y poder. Latinoamérica en el siglo XIX (Santiago de Chile, Fondo de Cultura Económica, 2011).

Matta, Enrique - Feliú, Guillermo (compiladores), Colección de historiadores y documentos relativos a la Independencia de Chile (Santiago de Chile, Imprenta Cervantes, 1911), XIX.

NAVARRO, Luis, El reformismo borbónico: proyectos y realidades, en BARRIOs, Feliciano, El Gobierno de un Mundo: virreinatos y audiencias en la América hispánica, (Cuenca, Ediciones de la Universidad de Castilla-La Mancha, 2004).

Perdices de Blas, Luis - ReEder, John, El mercantilismo: política económica y Estado Nacional (Madrid, Editorial Síntesis, 1998).

Ruiz, Julián - García, Cristina, Cargadores a Indias (Madrid, MAPFre Ediciones, 1992).

Salinas, Carlos, La biblioteca de don Mariano Egaña, con especial referencia a sus libros de Derecho, en Revista de Estudios Histórico-Jurídicos, 7 (Valparaíso, 1982).

Sesiones de los Cuerpos Legislativos.

Silva, Raúl, Egaña en la Patria Vieja 1810-1814 (Santiago de Chile, Editorial Andrés Bello, 1959). 
SiLva, Raúl, Juan Egaña. Escritos inéditos y dispersos (Santiago de Chile, Imprenta Universitaria, 1949).

ValenCia, Luis, Anales de la República (2a Edición, Santiago de Chile, Editorial Andrés Bello, 1986), I.

Villalobos, Sergio, El comercio extranjero a fines de la dominación española, en Journal of Inter-American Studies, 4 (Miami, 1962).

Villalobos, Sergio, El comercio y la crisis colonial (Santiago de Chile, Ediciones de la Universidad de Chile, 1968). 